Archives de sciences sociales des religions

172 | octobre-décembre

Bulletin Bibliographique

\title{
Nathalie Richard, La Vie de Jésus de Renan. La fabrique d'un best-seller
}

Rennes, Presses universitaires de Rennes, coll. « Histoire », 2015, 316 p.

Frédéric Gugelot

\section{OpenEdition}

\section{Journals}

Édition électronique

URL : http://journals.openedition.org/assr/27443

DOI : $10.4000 /$ assr. 27443

ISSN : $1777-5825$

Éditeur

Éditions de l'EHESS

Édition imprimée

Date de publication : 1 octobre 2015

Pagination : 355

ISBN : 978-2-7132-2515-4

ISSN : 0335-5985

\section{Référence électronique}

Frédéric Gugelot, «Nathalie Richard, La Vie de Jésus de Renan. La fabrique d'un best-seller », Archives

de sciences sociales des religions [En ligne], 172 I octobre-décembre, mis en ligne le 09 juin 2016, consulté le 24 septembre 2020. URL : http://journals.openedition.org/assr/27443 ; DOI : https:// doi.org/10.4000/assr.27443

Ce document a été généré automatiquement le 24 septembre 2020

(C) Archives de sciences sociales des religions 


\section{Nathalie Richard, La Vie de Jésus de Renan. La fabrique d'un best-seller}

Rennes, Presses universitaires de Rennes, coll. « Histoire », 2015, 316 p.

Frédéric Gugelot

\section{RÉFÉRENCE}

Nathalie Richard, La Vie de Jésus de Renan. La fabrique d'un best-seller, Rennes, Presses universitaires de Rennes, coll. « Histoire », 2015, 316 p. 
1 En l'année 1863, l'éditeur Michel Lévy vend en France 70000 exemplaires d'une Vie de Jésus. En dix-huit mois, 146000 ouvrages sont mis en circulation. C'est un best-seller. Le mot commence alors à se diffuser, qui établit le magistère intellectuel et la fortune de son auteur, Ernest Renan. Sainte-Beuve n'hésite d'ailleurs pas à comparer ce succès à la création, la même année, du Petit Journal, premier grand quotidien populaire (p. 9 et 133). Dès l'année suivante, l'auteur et l'éditeur publient une variante "populaire» intitulée Jésus, « un Christ simple et pur comme le sentiment qui le créa » précise-t-il (p. 235), allégée, plus didactique car moins érudit, partiellement décontextualisé, idéalisé, financièrement plus accessible. 80000 exemplaires sont écoulés dans l'année. S'y accentue la
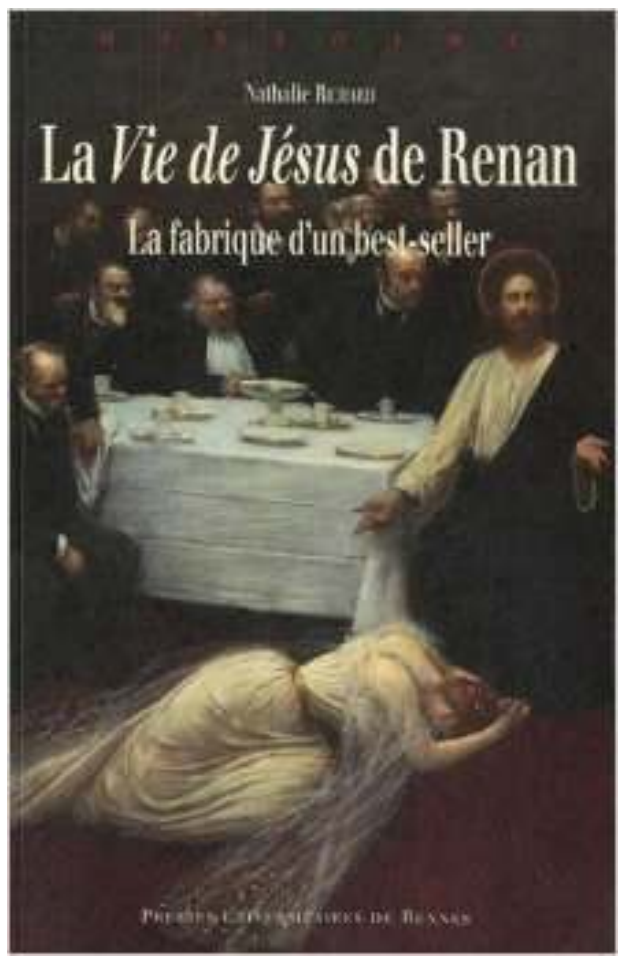
posture de l'auteur comme prophète s'appuyant sur l'autorité du savant, proposant une religion de l'amour, dégagée des superstitions, sans temple et sans prêtre, un moyen d'accès à un état de communion spirituelle propice à la connaissance de soi. La Vie de Jésus est une étape intellectuelle du siècle. Nathalie Richard nous en livre avec une grande réussite les enjeux.

2 Le livre fait donc événement. Il est interprété immédiatement comme « le signe d'une rupture culturelle, sociale et politique plus fondamentale » (p. 11). En fait, Ernest Renan a conçu dès l'origine son livre comme destiné à un public large, il est conscient qu'un nouveau lectorat s'ouvre au milieu du siècle. L'éditeur dans le même temps mène une vraie politique de quête d'auteur, fait un usage habile de l'effet de nouveauté et de stratégies commerciales adaptées aux nouveaux secteurs de public (presse, format des ouvrages, réseaux de diffusion). Le P. Joseph Félix, prédicateur de Notre-Dame, le constate : «Ce succès avait été préparé de longue main, et avec une habilité rare. [...] La Vie de Jésus n'était pas encore sous les presses de M. Lévy; elle s'élaborait à peine dans la forte tête de M. Renan, que déjà elle galvanisait l'opinion. » (p. 30).

Renan s'appuie sur une érudition déjà reconnue sur les questions religieuses qu'il revendique dès l'introduction: «Pour faire l'histoire d'une religion, il est nécessaire premièrement d'y avoir cru [sans cela on ne saurait comprendre par quoi elle a charmé et satisfait la conscience humaine]; en second lieu de n'y plus croire d'une manière absolue ; car la foi absolue est incompatible avec l'histoire sincère » (p. 192). Le projet intellectuel apparaît issu d'une conception rationaliste de la connaissance. Renan fonde sur l'observation empirique des faits humains la généralisation philosophique. Les religions apparaissent comme des créations humaines et donc des objets légitimes de la recherche historique. À l'aune de son propre cheminement, Renan pense les sciences historiques comme " source de vérité » (p. 50), elles prennent, à ses yeux, la place de la philosophie. D’où son choix d'user des Évangiles comme de documents sérieux dont il faut établir l'exégèse. Mais pour lui, la valeur d'une source ne réside pas dans la 
précision des faits mais dans l'absence d'élaboration du contenu. Il faut rechercher les lois qui organisent les données collectives, ce qui ne peut passer que par une comparaison. Décrire la naissance d'une nouvelle religion au Moyen-Orient au premier siècle de notre ère revient aussi à dégager les règles générales d'un tel processus, de saisir la ferveur religieuse et la croyance dans l'intervention providentielle telles qu'elles peuvent se déployer aussi au milieu du XIX siècle à Lourdes par exemple. L'analyse historique des faits collectifs serait la base d'une "psychologie historique » (p. 91).

4 Renan sait que ses thèses feront scandale et a acquis, par voie de presse, la réputation d'un penseur hardi. Il combat les dérives anti-rationalistes et dogmatiques du catholicisme, mais il aspire à mettre en accord sa foi et les exigences de son temps. Très tôt attiré par la figure de Jésus, il s'intéresse de près aux manifestations modernes du surnaturel, en particulier aux apparitions de la Vierge. D'où sa volonté de dégager les logiques et modalités d'une croyance collective au miracle, cette croyance devenant le véritable objet d'étude de l'historien. Ainsi Renan pense que Jésus ne croyait pas au surnaturel mais qu'il n'eut pas le choix : il devait « renoncer à sa mission ou devenir thaumaturge » (p. 102). Jésus est pour lui un grand homme, un « éclaireur » (p. 108) qui a fondé une religion nouvelle sur le sentiment de l'amour et l'idée de fraternité. Donc l'ancien séminariste remet en cause l'inspiration sacrée des textes évangéliques et défend une nature purement humaine du Christ : « Un homme incomparable - si grand que, bien qu'ici tout doive être jugé au point de vue de la science positive, je ne voudrais pas contredire ceux qui, frappés du caractère exceptionnel de son œuvre, l'appellent Dieu " (p.35). La démarche de l'auteur doit permettre le développement d'une science rationnelle des religions mais aussi participer à la rénovation du christianisme, à son adaptation au monde moderne. Le livre est «Traversées d'élans mystiques, échappant au modèle ascétique qui domine la très abondante littérature dévotionnelle qui paraît alors, proposant une spiritualité conçue comme une expérience personnelle hors des cadres institutionnels de l'Église» (p. 205). Renan croit que le peuple, tel qu'il l'imagine, dans une vision plus morale que sociale, attend un nouvel Évangile, un message religieux moderne, sans recours au surnaturel.

5 Si cette double ambition, scientifique et spirituelle, a brouillé son message, elle a démultiplié les lectures possibles dans une époque selon la presse où «nous voulons prier et croire, sans cesser pour cela de chercher, d'étudier, de réfléchir » (12 juillet 1863, p. 132), une «époque tourmentée par le besoin de croire " (10 septembre 1863 , p.131). Néanmoins, le livre ne s'inscrit pas dans la libre pensée rationaliste et l'anticléricalisme, ce qui n'empêche pas une partie de la presse satirique d'en user. Ainsi un journaliste propose de mettre au concours une liste de nouveaux miracles tels que « rendre les Jésuites populaires » ou « apprendre la politesse à M. Louis Veuillot de façon à lui faire publier un article de vingt-cinq lignes qui ne contienne pas soixante injures» (p. 145).

6 Très tôt, le camp catholique s'oppose au livre. On insiste sur l'apostasie de l'auteur. Ce «lévite infidèle " «donne à l'Homme-Dieu le baiser de Judas» (p. 151). Dès le mois d'avril 1863, Félix Dupanloup, évêque d'Orléans, publie un Avertissement à la jeunesse et aux pères de famille sur les attaques dirigées contre la religion par quelques écrivains de nos jours au titre si significatif tant de la distinction des publics que des rôles assignés à chacun par l'Église. La réputation du livre se forge donc au sein des médias. Et la multiplication des anathèmes contre le livre et l'auteur - la presse parle d'une 
«neuvième croisade» (1863-64, p. 168) - touche un public géographiquement et socialement très divers et constitue un relais vers les catégories rurales et populaires. La polémique amplifie la diffusion du livre. Cet «attentat contre toute l'Église catholique » (Mgr Cruice, évêque de Marseille, 1863, p. 180) est destructeur de l'ordre moral, social et donc politique. La critique catholique se divise sur deux stratégies qui reflètent les divisions de l'opinion catholique sur la question du dogme à un moment où les clercs romains insistent sur la soumission de la raison à la foi. La Vie de Jésus est alors présentée comme un roman et non une œuvre scientifique, perception d'ailleurs partagée par des proches. Taine note : " c'est mettre un roman à la place de la légende " (p. 195). Or le roman a mauvaise presse au sein de l'Église, le genre est perçu comme spirituellement dangereux, sentimental quand il n'est pas immoral et corrupteur. La Vie de Jésus joue certainement dans les nombreuses mises à l'Index en 1864 des principaux romanciers français. Ces différentes interprétations transforment l'essai exégétique en phénomène de mode qui dépasse le public urbain et cultivé d'autant que la dimension esthétique est souvent louée, promettant une lecture facile et historiquement et géographiquement exotique. L'audience du livre s'étend rapidement au-delà des cercles savants auprès d'un autre public, sur les franges éduquées des catégories populaires, ouvrières, féminines et paysannes. En déplaçant le livre de l'exégèse à la fiction, la critique catholique a sans doute favorisé son succès. L'abbé Guettée pense cette campagne contre-productive, ces "défenses n'empêcheront personne de lire le livre et ne feront que lui donner la saveur du fruit défendu " (p. 125). Les réfutations ont aussi contribué à le faire connaître, en donnant de larges extraits ainsi que les principaux arguments. Il devient un objet à avoir, une référence à évoquer. Les bons mots fleurissent évoquant le succès de la Vie de Jésus : une première dame demande à une autre de l'accompagner au bois, la seconde lui répond qu'elle ne peut pas car, plongée dans une lecture passionnante, elle veut absolument en connaître la fin.

7 Au sein des protestantismes et du judaïsme, les qualités romanesques de l'ouvrage sont considérées comme un manque de rigueur scientifique et certaines remarques de Renan sont perçues comme vecteur d'antisémitisme. Les correspondances reçues par l'auteur oscillent entre admiration et invective, entre adhésion et sollicitations. Les prêtres et les femmes y sont nombreux, les anonymes aussi. Certains y découvrent en effet une foi plus conforme à leur quête, une manière indépendante de penser sans rompre avec la croyance.

8 L'excellent ouvrage de Nathalie Richard permet ainsi à travers l'étude de la fabrique et de la réception d'un des best-sellers du XIX ${ }^{e}$ siècle, la Vie de Jésus de Renan, de dessiner les évolutions du champ littéraire, scientifique et religieux au milieu du XIX $\mathrm{X}^{\mathrm{e}}$. Ce succès se réalise grâce à une pluralité de lectures, reflet de la pluralité des lecteurs. Ceci est rendu possible par un ouvrage hybride, évolutif, dès le départ conçu comme pouvant toucher un large public. La version érudite atteint 22 rééditions entre 1867 et 1915, la version populaire connaît sa $80^{\mathrm{e}}$ édition en 1903. Les médias jouent un rôle essentiel, même la campagne catholique contre l'ouvrage a en fait favorisé sa diffusion. Renan devient un auteur célèbre. Pourtant s'il propose une religion rénovée compatible avec la société moderne, le livre divise. Le savant homme de lettres devient un membre du camp rationaliste ébranlant les fondements religieux et moraux de la société pour certains, une figure émancipatrice pour d'autres. Mais son influence fut éphémère. Son 
approche "psychologique " ne trouve pas de débouchés scientifiques, ses successeurs font d'autres choix épistémologiques. Le roman l'a emporté sur l'essai exégétique. 